\title{
HISTÓRIA DE VIDA E DINÂMICA POPULACIONAL DE HYALE NIGER (HASWELL, 1879) (AMPHIPODA, HYALIDAE) ASSOCIADA A SARGASSUM SP. (PHAEOPHYTA, FUCALES) EM UMA ÁREA COM HISTÓRICO DE CONTAMINAÇÃO
}

\author{
Mansur, K.F.R. ${ }^{1,}{ }^{*}$; Longo, P.A.S. ${ }^{1}$; Siqueira, S.G.L. ${ }^{1}$ \& Leite, F.P.P. ${ }^{1}$ \\ ${ }^{1}$ Universidade Estadual de Campinas (UNICAMP), Campus Campinas, \\ Laboratório de Interações entre Comunidades Marinhas. \\ *Autor correspondente: karinefrmansur@gmail.com
}

\begin{abstract}
A estrutura, dinâmica e elementos da história de vida de quatro populações do anfípode Hyale niger foram analisados mensalmente em quatro pontos com diferentes distâncias de um foco de poluição dentro da Enseada do Flamengo (Ubatuba, São Paulo): praias Lamberto e Ribeira, localizadas mais próximas ao foco de poluição; e praias Santa Rita e Flamengo, mais distantes. Em cada ponto, foram coletadas amostras de Sargassum sp. e todos os espécimes $H$. niger associados foram medidos para construção de tabelas de vida idades-específicas e para se estimar os parâmetros da função de crescimento de Von Bertalanffy. Os parâmetros de história de vida, como: densidade de indivíduos; número de ovos por fêmeas e índice reprodutivo; desempenho de crescimento e taxa de mortalidade; foram comparados entre as populações. As amostras de algas e seus epibiontes foram secas em estufa para obtenção da biomassa seca. A densidade de $H$. niger apresentou variação temporal e entre locais, mas não foi relacionada à biomassa de Sargassum sp. e epibiontes, descartando a possibilidade da disponibilidade de alimento e abrigo influenciarem a variação encontrada. A população do Lamberto, ponto mais próximo ao foco de poluição, apresentou menor número de indivíduos, maior taxa de mortalidade e menor índice reprodutivo, mas obteve o maior valor de desempenho de crescimento, indicando que os indivíduos investem mais em crescimento. Já a população da Ribeira, segundo ponto mais próximo ao foco de poluição, apresentou maior investimento em reprodução, com maior índice reprodutivo e menor desempenho de crescimento. A população do Flamengo, ponto mais distante do foco de poluição, apresentou número reduzido de indivíduos, impossibilitando as estimativas dos parâmetros de reprodução e crescimento. Em contrapartida, a população da Santa Rita apresentou maior número de indivíduos, com valores intermediários de índice reprodutivo e desempenho de crescimento, indicando que os indivíduos investem tanto em reprodução como em crescimento. Duas principais hipóteses são levantadas para explicar tais resultados: (1) a existência de pressões ambientais diferenciais entre os locais, possivelmente relacionadas às diferentes distâncias do foco de poluição e, portanto, a diferenças de exposição a contaminantes gerados; (2) a existência de uma metapopulação em toda a enseada, sendo que o padrão hidrodinâmico da região estaria influenciando nas diferenças estruturais encontradas para as subpopulações em cada local.
\end{abstract}

Palavras-chave: macroalga, fauna, tabela de vida, Von Bertalanffy, fecundidade. 